\title{
Standards and Stories: The Interactional Work of Informed Choice in Ontario Midwifery Care
}

\section{Normes et narration : travail interactif autour des choix éclairés dans l'exercice des sages-femmes en Ontario}

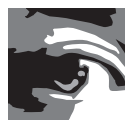 \\ PHILIPPA SPOEL, PHD \\ Professor, Department of English \\ Laurentian University \\ Sudbury, ON \\ PAMELA MCKENZIE, PHD \\ Associate Professor \\ Faculty of Information and Media Studies \\ University of Western Ontario \\ London, ON \\ SUSAN JAMES, PHD \\ Associate Professor, Midwifery Education Program / \\ Programme de formation des sages-femmes \\ Laurentian University \\ Sudbury, ON \\ JESSICA HOBBERLIN \\ Researcher, Midwifery Education Program / \\ Programme de formation des sages-femmes \\ Laurentian University \\ Sudbury, ON
}

\begin{abstract}
This paper uses a discourse-rhetorical approach to analyze how Ontario midwives and their clients interactionally accomplish the healthcare communicative process of "informed choice." Working with four excerpts from recorded visits between Ontario midwives and women, the analysis focuses on the discursive rendering during informed choice conversations of two contrasting kinds of evidence - professional standards and story-telling - related to potential interventions during labour. We draw on the concepts of discursive hybridity (Sarangi
\end{abstract}


and Roberts 1999) and recontextualization (Linell 1998; Sarangi 1998) to trace the complex and creative ways in which the conversational participants reconstruct the meanings of these evidentiary sources to address their particular care contexts. This analysis shows how, though very different in their forms, both modes of evidence function as hybrid and flexible discursive resources that perform both instrumental and social-relational healthcare work.

\section{Résumé}

Cet article emprunte une démarche rhétorique pour analyser la façon dont les sages-femmes et leurs clientes en Ontario accomplissent de façon interactive les processus de communication en santé pour faire des « choix éclairés ». À l'aide de quatre extraits enregistrés lors de rencontres entre sages-femmes et femmes en Ontario, l'analyse se penche sur le rendu discursif de deux types distincts de données - les normes professionnelles et la narration d'anecdotes au cours de conversations portant sur un choix éclairé au sujet d'une possible intervention pendant le travail. Nous employons les concepts de l'hybridité discursive (Sarangi et Roberts 1999) et de la recontextualisation (Linell 1998; Sarangi 1998) pour retracer les chemins complexes et créatifs qu'empruntent les participantes pour reconstruire la signification des sources de données afin d'aborder leur propre cas. Cette analyse montre comment, bien que sous des formes différentes, les deux modes de données fonctionnent comme des ressources discursives hybrides et flexibles qui agissent tant au niveau instrumental que socio-relationnel.

\section{His paper examines how ontario midwives and their Clients interactionally accomplish "informed choice" in clinic visits by calling on and negotiating two contrasting kinds of evidence: (a) authoritative guidelines articulated} in professional standards and community protocols and (b) social stories told by midwives as they talked with women about healthcare options. How do participants recontextualize the meanings of these different evidentiary sources to address their particular care contexts? Our analysis indicates that participants invoke evidence in ways that combine instrumental and social talk to perform both clinical and relational functions. The interaction thus enacts a hybrid discourse, simultaneously reflecting and reproducing midwifery's relational-feminist goals and the requirements of regulated healthcare.

\section{Context}

In Canada and internationally, informed choice is recognized as integral to midwifery care (e.g., International Confederation of Midwives; Canadian Midwifery Regulators Consortium). In Ontario, the first province to regulate midwifery as a primary care profession (Ontario Midwifery Act 1991), the College of Midwives (1994/2005) defines informed choice as involving "a co-operative and collaborative information exchange between the midwife and the woman" that supports "the woman as primary decision-maker." Consonant with its roots in the alternative childbirth and women's health movements of the 1970s, this model explicitly 
values the exchange of diverse forms of evidence, including emotional, intuitive, spiritual and narrative ways of knowing along with more biomedical and scientific modes (Davis-Floyd and Davis 1996; James 1997; MacDonald 2006).

However, Ontario midwives also practise within a network of professional responsibilities and provincial regulations (Bourgeault 2006). According to MacDonald (2007), the practical and ideological challenges of becoming regulated have resulted in a complex, dynamic reworking of the relationship between midwifery's "alternative" philosophy of "natural" childbirth and biomedical approaches to pregnancy. Contemporary midwifery therefore somewhat uneasily combines both the holistic, woman-centred ideology of pre-regulation practice and the dominant biomedical discourses that shape regulated Canadian healthcare (Spoel 2006, 2007).

Because of midwifery's position at the intersection of mainstream and alternative healthcare ideologies, informed choice functions as an important communicative process for negotiating healthcare norms, knowledges and identities. According to Spoel (2010), discursive hybridity constitutes a defining feature of Ontario midwifery's informed choice communication. Discursive hybridity "captures the complex and multi-layered nature" of healthcare work and communication practices by conceptualizing the "shifting modalities" that characterize these practices and situations (Sarangi and Roberts 1999: 62). Here, we explore how midwives and women creatively and strategically invoke and negotiate diverse forms of evidence during informed choice conversations to address "the ever-changing demands and contradictions of real social situations" (Sarangi 2000: 12).

\section{Methodology}

Our data set comprises transcripts of 48 clinic visits between Ontario midwives and clients. McKenzie recorded single visits in 15 southern Ontario midwifery practices between 40 women and each woman's midwife. Spoel and James recorded eight northern Ontario visits, four each for two women and their midwifery teams. Our data, collected between 2002 and 2007, provide a window into the midwife-woman interaction at an important period in the development of regulated midwifery in Ontario. Our research conforms to Canadian ethical guidelines (CIHR et al. 2003). Practices have been anonymized, and all participants are identified here by role (midwife, client, student midwife).

Our discursive-rhetorical approach focuses on "the study of language in use" (Wetherell et al. 2001: 2). First, we analyzed our transcripts thematically to identify informed choice conversations. We then analyzed these discussions discursively, attending to the ways midwives and women discuss evidence relating to the decision to be made. Our analysis focuses on the characteristics of the talk itself: we closely studied the details of language and attended to similarities and variations both within and across accounts. We thereby identified the forms of evidence used, the strategies speakers used when making a case, the rhetorical functions that cases or counter-cases might serve and the potential consequences of such presentations. The analytic method is similar to constant comparison (Strauss and Corbin 1990), but with the goal of identifying and describing the presentation of evidence rather than developing grounded theory. 
For this paper, we highlight discussions of potential interventions during labour. We interpret "evidence" broadly to mean diverse formal and informal types of information that participants draw on directly and indirectly to explain, challenge or support decisions. Such information includes, for example, professional standards and protocols, clinical and alternative healthcare research, records and test results, personal and professional experience, and popular culture.

Our concept of evidence aligns with the rhetorical distinction between extrinsic proof ("facts" or objects of evidence that exist outside of or prior to the rhetorical exchange) and intrinsic proof (the art of creating persuasive arguments, often through the discursive interpretation of extrinsic sources of evidence). Because extrinsic evidence cannot speak for itself, rhetoric crafts proofs that allow us to share understandings, form judgments and take actions (Hauser 1986; Hill 1995).

When participants in a rhetorical exchange invoke extrinsic sources of evidence, they do not simply transfer the meanings of these sources into their exchanges. Rather, they engage in recontextualization: "the dynamic transfer-and-transformation of something from one discourse/text-in-context ... to another" (Linell 1998: 144). Recontextualization is "a rerendering of context": through creative and strategic uses of prior text, participants redefine the context. Context is dynamic, acting as both resource and constraint on participants' meaning-making (Sarangi 1998: 307). Aspects of discourse that may be recontextualized include "linguistic expressions, concepts and propositions, 'facts', arguments and lines of argumentation, stories, assessments, values and ideologies, knowledge and theoretical constructs, ways of seeing things and ways of acting towards them, ways of thinking, and ways of saying things" (Linell 1998: 144-45).

Here, we highlight two types of recontextualized extrinsic evidence within informed choice conversations: (a) references to professional healthcare standards or protocols and (b) recounted stories based on participants' prior experience. Invocations of these two different sources of evidence may be understood as enacting correspondingly different discursive modes: an expert-professional, instrumental mode led by the midwife, versus a mode that is more clearly sociable, collaborative and relational (Holmes and Marra 2005; McCourt 2006; Spoel 2010). The discursive hybridity of informed choice communication occurs, in part, through the mixing of these contrasting invocations. However, each mode likewise may be accomplished in hybrid ways such that "professional" talk about healthcare protocols also enacts relational functions, and sociable talk also accomplishes instrumental clinical tasks. Below, we explore these hybrid interactions and functions by analyzing two excerpts that reference healthcare protocols and two story-telling excerpts.

\section{Findings and Discussion}

\section{Professional standards and informed choice}

Professional standards and protocols are one source of extrinsic evidence that midwives and clients draw on in informed choice discussions. These standards range from those officially 
articulated by professional bodies such as the College of Midwives of Ontario and the Society of Obstetricians and Gynaecologists of Canada to more situated community standards and institution-based policies as well as best practice developed by local hospitals and physicians. Because these protocols simultaneously enable and constrain the options available to midwives and women, their invocation within midwife-client conversations functions as an important space of discursive negotiation across professional-institutional boundaries, as well as within professional-client encounters (Sarangi 1998: 302).

The following two excerpts focus on protocols concerning testing and treatment for Group B Streptococcus (GBS), a key topic of informed choice discussion in midwifery care. GBS is a common bacterium, present in $10 \%-30 \%$ of women. Although colonization is typically temporary and asymptomatic, GBS infection is the leading cause of life-threatening infectious disease in newborns. The overall incidence of neonatal GBS disease in Canada is 0.64 per thousand live births, with mortality rates ranging from 5\%-20\%. Risk factors for neonatal infection include prolonged rupture of membranes before delivery (Money and Dobson 2004). In the past 10 years, North American clinical guidelines have changed rapidly and have been inconsistent across Ontario communities (Burkell and McKenzie 2005).

\section{EXCERPT (A):}

Midwife: And too, you know, [client], things may have changed since last time around in community clinical standards and options you have.

\section{Client: Yeah.}

Midwife: Ruptured membranes without labour. Now they're offering inductions [after] 6 to 12 hours, when maybe they were offering it at 18 . We still will wait until $18 . .$.

Client: Are you, are you bound by anything?

Midwife: Our college, our college says we must consult at, ah, when it's a prolonged ruptured membrane, ah, without labour and it's still technically being defined as ... the 18 hours. There's no absolute gold standard definition ... . In other communities, they don't intervene until 24 or 48 hours ... . So, and you have the option to wait. Remember you always have a choice to say, "I choose ...."

Client: Yeah. 
The second excerpt addresses standards concerning "swabbing" for GBS and the potential implications for permissible time lapse between ruptured membranes and induction:

\section{EXCERPT (B):}

Midwife: If you were in care with a physician or an obstetrician here in [city], the community standard is not to do a swab.

Client: Okay. So, that's fine.

Midwife: So, and the Society of Obstetricians and Gynaecologists, they put out a protocol for that and they said there are two equally acceptable strategies. And one is what's happened here in [city], where nobody gets swabbed with, you know, physicians and obstetricians. But what they do instead of giving the swab, is if in labour you develop a risk factor, that's when they would give you antibiotics. So, if you have fever, if your water had been broken for a very long time, that kind of thing.

\section{Client: Okay.}

Midwife: For people ... , when we look at those risk factors. People who, uhm, would think about if your water had broke and you didn't go into labour. If you're a person who did want to push the limit and give your body every chance to go into labour on its own, it may be a good idea to have the swab, to give you extra information.

Client: Yeah.

Midwife: Ah, here in [city], the community standard says if your water breaks and you're not in labour by, you know, 6 to 12 hours, they are recommending that you go in and do a consult and have antibiotics. Our college, the College of Midwives, says 18 hours.

\section{Client: Right.}

Midwife: So, I would be required to consult at 18 hours. But typically, with OBs they, they've even become more conservative here.... the other factor that plays into this is the community in which we work, practise with. We peer-review with [other Ontario city]. They have people with ruptured membranes for 7 days. [laughing] And it, you know, it's very different. Here, we have a 12 -hour ... . So it's, it's really, you know, and unfortunately I guess anybody who lives here gets, unh you have to, you know, you ... work with where you're, where you're practising. 
Standards and Stories: The Interactional Work of Informed Choice in Ontario Midwifery Care

Client: Yeah.

Midwife: But at the same time, you have choices.

Client: Mhmm.

Midwife: And you can say, "Well, I think they do this differently in some places than in [this city]"

These excerpts show the dynamic, situated ways in which the participants recontextualize the professional protocols that structure the choices available to women. The standards' meanings and functions are reconfigured within the exchange to "fit" (Linell 1998: 144) the context of each midwife-client situation. Although these excerpts recontextualize in unique ways, they share discursive features that may indicate characteristic ways in which Ontario midwives and women reconstitute the evidentiary authority of extrinsic standards within informed choice communication. A discussion of these characteristic ways follows.

\section{NAMING SOURCES OF AUTHORIZATION}

The midwives identify the sources of authorized standards by naming specific professionalregulatory bodies, by referencing the more ambiguous source "community" and through plural personal and impersonal pronouns ("our," "they"). The midwife in Excerpt (a) refers to "community clinical standards and options." Her subsequent reference to the standard of "our college" (i.e., the College of Midwives of Ontario) contrasts with the "they" of the medical profession or local hospital. This juxtaposition constructs the context as involving potentially conflicting regulatory frameworks, that of the local medical community and that of the provincial midwifery college.

Similarly, the midwife in Excerpt (b) provides context for her client's decision by explaining that the Society of Obstetricians and Gynaecologists of Canada (SOGC), subsequently identified as "they," has "put out a protocol" on this. She also refers to "the community standard" concerning how much time may elapse between a woman's membranes rupturing and labour being induced, and contrasts this with the protocol of "our college, the College of Midwives." In so doing, she discursively establishes the distinctiveness of midwifery care in contrast with physician care, yet at the same time represents the context as shaped by diverse but interacting standards.

\section{NAMING THOSE WHOSE DECISIONS THESE STANDARDS SHAPE}

The midwives and the clients name themselves - mainly through the pronouns "we" and "you" - as those whose decisions and actions are affected by the protocols being discussed. Midwives use "we" to identify themselves as members of the midwifery profession; "you" identifies the other speaker in the interaction. However, the specific attributions are ambiguous: 
"We", for example, seems to refer partly to the whole midwifery profession and partly to each localized midwifery practice, with its situated strategies for negotiating "community standards." Similarly, the pronoun "you" when used by each midwife refers both to the specific client being addressed and to a generic "you" who may (or may not) be affected by the protocols being discussed. In Excerpt (b), "you" becomes "people." This substitution ambiguates the context as one in which the midwife recommends a strategic action to this specific client in light of the SOGC protocol and one that is generically, but perhaps not specifically, applicable to this woman's decisions.

\section{VERBS OF PERMISSION}

The presence of verbs signifying the boundaries of permission and prohibition strongly indicates how protocols affect the context of informed choice. The client in Excerpt (a) asks whether the midwife is "bound by anything." Her midwife replies, "our college says we must consult at ... 18 hours." The midwife in Excerpt (b) says that she "would be required to consult at 18 hours" (our emphases). These verbs index participants' concern about how diverse standards define the possible courses of action they may take. Notably, the midwives represent themselves as accountable principally to their own profession's standards rather than "community" or medical protocols, though in a way that avoids directly opposing non-midwifery standards.

\section{CHARACTERIZING STANDARDS AS SITUATIONAL}

Concomitantly, the midwives unsettle the constraining authority of the invoked standards by alluding to the situational, interpretable nature of healthcare protocols. By stressing that "in other communities, they don't intervene until 24 or 48 hours," the midwife in Excerpt

(a) frames the context as one in which protocols are variable and interpretable. The midwife in Excerpt (b) likewise notes, "you have to ... work with where you're ... practising," such as working with obstetricians who have "even become more conservative here." This rendering of local context reinforces how the meanings and functions of standards are contingent and at least somewhat negotiable across and within professional-institutional boundaries.

\section{RE-ASSERTING “CHOICE” AS CONTEXTUALLY RELEVANT}

This discursive move reconfigures the context as one in which (despite appearances to the contrary) the principle of informed choice still applies. The midwife in Excerpt (a) uses the evidence that "other communities" have different guidelines for the length of time women may avoid intervention after membranes rupture as the warrant for reminding her client that "you have the option to wait. Remember you always have a choice to say, 'I choose." Similarly, the midwife in Excerpt (b) closes the sequence by contrasting the "conservative" standards of the local community with the client's right to make her own choices. Both discursively construct the hypothetical context in which clients might claim their right to choose by rehearsing, through future-oriented reported speech, what women can say. By representing the client as 
able to question the authority of "community" standards, the midwives enact the possibility that the principle of informed choice is not compromised by these standards. However, the clients' non-committal response tokens ("yeah"; "mhmm") suggest they are less concerned than the midwives about the possible infringement on their right to informed choice.

Although these excerpts perform primarily a kind of instrumental, task-oriented "business talk," in which the midwife fulfills her role as expert information provider to the client as information receiver (Spoel 2010), they also accomplish important relational functions interprofessionally, intraprofessionally and between midwife and client. These excerpts render the context of interprofessional relations as one that calls on midwives to "work with" physicians in the community even when midwifery and medical standards differ; intraprofessionally, the individual midwives position themselves as relationally accountable to the corporate authority of "our college"; most significantly, how the midwives recontextualize the protocols strengthens their relational alignment with their clients because it presumes and reinforces shared concerns about the need to respond strategically to "conservative" medical protocols. This mixing of instrumental professional discourse with more relational-social discourse likewise occurs in the story-telling evidence discussed below, though here the interactions' social functions are initially most obvious.

\section{Story-telling and informed choice}

In interactions between healthcare professionals and their clients, social talk may be inextricably enmeshed with more instrumental talk, and relational and instrumental goals may be interdependently achieved (Ragan 2000; Sharpe 2004). The enmeshing of social talk into clinical midwifery care reflects the explicitly woman-centred goals of the profession, and the telling of informal stories helps to accomplish these goals. The following two excerpts show how informal story-telling that appears initially to be entirely social also does the professional work of informed choice.

The first excerpt comes from a visit between a woman and the midwife who had attended her previous birth. A student midwife was also present. After discussing the woman's ambivalence towards epidural pain relief, the client told a story about using nitrous oxide gas during her previous labour, and the midwife responded with a story of her own.

\section{EXCERPT (C):}

Client: It makes me kinda laugh because it was, like, I remember when it was time to take the gas for pushing and you said, "I think it's time," and [starts laughing as she talks] I remember thinking, "I'm gonna kill you!"

All: [laughter from all sides]

Client: I was looking at [midwife] thinking,"I'm gonna kill you." 
All: [laughter]

Midwife: You wouldn't be the first person.

Midwifery student: [laughs]

Client: No, I know.

Midwife: [changing voice to imitate woman in labour] "What do you mean I have to give it back?"

All: [laughter]

Client: You don't like to, ah, be the one to deliver the bad news.

Midwife: Yeah. Well, I had, ... I think it was the first person actually that we had her baby at [birthing centre], ... and it was ... her first baby and she was about 8 centimetres dilated, and so she was kind of needing something, so we gave her the gas and she sorta took one big hit off it and she stood up on the bed and said, "I love this stuff!!"

All: [laughter]

Client: On the bed?

Midwife: On the bed!

All: [laughter]

Midwife: Woo!!

Client: Oh my goodness.

Midwifery student: Wow.

The second excerpt is from a conversation of home birth plans. It begins partway through a discussion of plans for labour and birth in the basement, after which the midwife tells a story: 
Standards and Stories: The Interactional Work of Informed Choice in Ontario Midwifery Care

\section{EXCERPT (D):}

Midwife: Of course we want you to stay on whatever level you are on for the first day roughly.

Client: Yeah.

Midwife: No long trips up stairs.

Client: That's fine, yeah. Yeah, because there's eight, six [steps], plus another eight to get up.

Midwife: Lots of landings, so -

Client: Yeah, so the, yeah -

Midwife: Or [partner] will have to carry you [laughs].

Client: Yeah, oh god!

Midwife: Come have a seat really quick so I can do your blood pressure.

Client: Let me take this off.

Midwife: I had clients and it was very funny, they wanted a home birth so I had home visits because they do live fairly locally. Of course, we do visits in our primary care area, but for people who live that far away ... we tell them call an ambulance, the reason being, you're far enough out that we're not going to get to you in time.

Client: Um-hum.

Midwife: So I didn't know that she had four flights of stairs in her apartment building that she had to walk when she went home.

Client: Oh, my gosh!

Midwife: Yeah [silent 4 seconds] - one-ten on sixty. So I gave them a call, we had a daytime birth, I gave them a call just to say how are things going, are you accelerating nicely, all of that, and she went, "Oh, everything went fine, well, except for me getting light-headedness" and I went, "Oh, well, tell me about it" and she told me that she tried to do all flights at once. 
Client: Oh, my.

Midwife: Yeah.

Client: Well, that's what I could kind of see happening.

Midwife: I felt awful, doing the home assessment without identifying that...

\section{Client: Oh.}

Midwife: So, I had to change the assessment when we do prenatal [to], "So, what's the layout, are you going to be walking up four flights of stairs?"

Both excerpts include much laughter, and the casual tone suggests comfortable conversations that build rapport but seem only marginally related to professional tasks. We argue, however, that these stories were also clinically relevant. The following micro-interactional characteristics indicate the stories' combined social-instrumental function.

\section{ACTIVE PARTICIPATION}

As is typical in women's friendly conversation, each story recontextualizes the immediately preceding discussion by mirroring the topical talk or specific elements of a previous story: a woman's strong positive response to nitrous oxide in labour and a birth in a dwelling with many stairs. Second, all participants actively contribute to the lighthearted telling of the stories through shared narration, encouraging responses (e.g., "wow") and sympathetic laughter (Coates 1996). These also are stories of benign misadventure that may show the teller in a self-deprecating light.

\section{INTEGRATING STORIES WITH THE “WORK” OF THE VISIT}

The stories flow from focused talk about potential interventions or bubble up in quiet spaces afforded by routine physical activities such as taking blood pressure. The casual conversation therefore does not interfere with the business of the encounter. As a result, these forms of talk appear inconsequential, yet they may unobtrusively accomplish - or assist in accomplishing significant professional tasks.

\section{NAMING EXPERIENTIAL AUTHORITIES}

In both excerpts, midwife and woman recontextualize their prior experiences as a source of authority. The client's initial story draws on the extrinsic evidence of her previous labour, while the midwives also invoke their past experiences as caregivers during labour and represent themselves as witnesses of women's experiences. Using this technique allows the midwife simultaneously to validate women's embodied experiences and to present herself as an authority on those experiences (McKenzie and Oliphant 2010). 


\section{SPECIFYING THE EXPECTED RESPONSE}

In each excerpt, the teller recontextualizes past events in a story to be heard as humorous, thus shaping how the listener should interpret it. The tellers of these remembered stories are accorded the authority to prescribe the meaning of the story for the current context. Although listeners may challenge prescribed meanings, they do not do so in these excerpts.

\section{GIVING ADVICE WITHOUT APPEARING TO DO SO}

Although these stories exhibit characteristics of lighthearted social talk, they are by no means "merely" social or off-topic. Midwives' stories, especially, can be seen as doing informed choice work in an interactionally delicate situation: giving advice without appearing to do so. Ontario midwifery's ideal of informed choice divides the cognitive labour: informing is the midwife's responsibility; deciding is the client's job (McKenzie 2009: 166). Many midwives in our sample interpreted this division as a directive to present information in a neutral way and actively resisted giving their clients direct advice. In this situation, story-telling may function as an important discursive strategy for indirectly advising women.

In Excerpt (c), the midwife uses a humorous story of another woman's experience to recontextualize the client's desire for pain relief as legitimate and tacitly endorses gas as a form of pain relief consistent with a "natural" midwife-assisted birth. In Excerpt (d), the midwife's story develops a negative exemplar of what might go wrong if the client chooses a course of action different from the one just proposed. Recontextualizing a course of action within a humorous story meets each midwife's combined social-clinical goals for a particular client and a particular visit, in a way that subtly guides the woman's choices to align with the midwife's professional opinion. Social stories about past experiences allow the midwife to assert her expert-professional authority to arbitrate the woman's choices without being seen to compromise her right to choose.

\section{Conclusion}

For midwifery in many Canadian as well as international jurisdictions, informed choice is a central but complex dimension of its woman-centred model of care. The diverse kinds of "evidence" that midwives and women draw on in their healthcare conversations constitute an important rhetorical space for negotiating the possibilities of informed choice in the context of regulated healthcare.

Closely analyzing excerpts in which participants invoke professional protocols and informal stories illustrates the multi-layered, dynamic ways in which these Ontario midwives and women construct the meanings and functions of these forms of evidence. Our analysis adds to the scholarly conversation about authoritative knowledge in maternity care by showing that these forms of evidence are not simply pre-established, external sources of information to which participants refer; rather, through each situated interaction, midwives and women recontextualize what these evidentiary sources mean within that particular setting. Despite notable differences between professional standards and story-telling as modes of evidence, both function as hybrid and flexible discursive resources, performing both instrumental and 
social-relational work. This finding contributes to our understanding of the complex, creative ways in which midwives and their clients interactionally accomplish informed choice. It also confirms the value of using a discourse-rhetorical approach to researching healthcare communication.

\section{ACKNOWLEDGEMENTS}

Pamela McKenzie's research was supported by a University of Western Ontario internal research grant and a Social Sciences and Humanities Research Council (SSHRC) Standard Research Grant. Philippa Spoel and Susan James's research was supported by a SSHRC Institutional Grant 4A award, Laurentian University.

Correspondence may be directed to: Philippa Spoel, Department of English, Laurentian University, Sudbury, ON P3E 2C6; tel.: 705-675-1151, ext. 4345; e-mail: pspoel@laurentian.ca.

\section{REFERENCES}

Bourgeault, I.L. 2006. Push! The Struggle for Midwifery in Ontario. Montreal: McGill-Queen's University Press.

Burkell, J. and P.J. McKenzie. 2005. "Information Provision for Informed Prenatal Decision Making." Canadian Association for Information Science Annual Conference. Retrieved June 27, 2013. <http://www.cais-acsi.ca/proceedings/2005/burkell_2005.pdf>.

Canadian Institutes of Health Research (CIHR), National Sciences and Engineering Research Council (NSERC) and Social Sciences and Humanities Research Council (SSHRC). 2003. TriCouncil Policy Statement: Ethical Conduct for Research Involving Humans. Ottawa: Public Works and Government Services Canada. Retrieved June 27, 2013. <http://pre.ethics.gc.ca/archives/tcps-eptc/docs/TCPS\%20October\%202005_E.pdf>.

Coates, J. 1996. Women Talk: Conversation between Women Friends. Cambridge, MA: Blackwell.

College of Midwives of Ontario. 1994/2005. "Informed Choice Standard." Retrieved June 27, 2013. <http://www. cmo.on.ca/informed_choice.php $>$.

Davis-Floyd, R. and E. Davis. 1996. "Intuition as Authoritative Knowledge in Midwifery and Homebirth." Medical Anthropology Quarterly (New Series) 10(10): 237-69.

Hauser, G.A. 1986. Introduction to Rhetorical Theory. Prospect Heights, IL: Waveland Press.

Hill, F.I. 1995. "Aristotle's Rhetorical Theory." In J.J. Murphy and R.A. Katula, eds., A Synoptic History of Classical Rhetoric (2nd ed.) (pp. 51-109). Davis, CA: Hermagoras Press.

Holmes, J. and M. Marra. 2005. "Narrative and the Construction of Professional Identity in the Workplace." In J. Thornborrow and J. Coates, eds., The Sociolinguistics of Narrative (pp. 193-213). Philadelphia: John Benjamins.

James, S. 1997. “Regulation: Changing the Face of Midwifery?” In F.M. Schroff, ed., The New Midwifery: Reflections on Renaissance and Regulation (pp. 181-200). Toronto: Women's Press.

Linell, P. 1998. “Discourse Across Boundaries: On Recontextualizations and the Blending of Voices in Professional Discourse." Text 18(2): 143-57.

MacDonald, M. 2006. “Gender Expectations: Natural Bodies and Natural Births in the New Midwifery in Canada." Medical Anthropology Quarterly 20(2): 235-56.

MacDonald, M. 2007. At Work in the Field of Birth. Nashville, TN: Vanderbilt University Press.

McCourt, C. 2006. "Supporting Choice and Control? Communication and Interaction between Midwives and Women at the Antenatal Booking Visit." Social Science and Medicine 62(6): 1307-18.

McKenzie, P.J. 2009. “Informing Choice: The Organization of Institutional Interaction in Clinical Midwifery Care.” Library and Information Science Research 31(3): 163-73. 
McKenzie, P.J. and T. Oliphant. 2010. “Informing Evidence: Claimsmaking in Midwives' and Clients' Talk about Interventions." Qualitative Health Research 20(1): 29-41.

Money, D.M. and S. Dobson. 2004."The Prevention of Early-Onset Neonatal Group B Streptococcal Disease." Journal of Obstetrics and Gynaecology Canada 26(9): 826-32.

Ontario Midwifery Act, SO 1991, c. 31. Retrieved June 27, 2013. <http://www.e-laws.gov.on.ca/html/statutes/ english/elaws_statutes_91m31_e.htm>.

Ragan, S.L. 2000. “Sociable Talk in Women's Health Care Contexts: Two Forms of Non-Medical Talk.” In J. Coupland, ed., Small Talk (pp. 269-87). London: Longman.

Sarangi, S. 1998. "Rethinking Recontextualization in Professional Discourse Studies: An Epilogue." Text 18(2): 302-18.

Sarangi, S. 2000. “Activity Types, Discourse Types and Interactional Hybridity: The Case of Genetic Counselling." In S. Sarangi and M. Coulthard, eds., Discourse and Social Life (pp. 1-27). London: Pearson.

Sarangi, S. and C. Roberts. 1999. “Introduction: Discursive Hybridity in Medical Work.” In S. Sarangi and C. Roberts, eds., Talk, Work and Institutional Order: Discourse in Medical, Mediation and Management Settings (pp. 61-74). Berlin: Mouton de Gruyter.

Sharpe, M.J.D. 2004. Intimate Business: Woman-Midwife Relationships in Ontario, Canada. Unpublished doctoral dissertation. Ontario Institute for Studies in Education, University of Toronto.

Spoel, P. 2006. "Midwifery, Consumerism and the Ethics of Informed Choice." In P.L. Twohig and V. Kalitzkus, eds., Bordering Biomedicine: Interdisciplinary Perspectives on Health, Illness and Disease (pp. 198-213). Amsterdam: Rodopi.

Spoel, P. 2007. "A Feminist Rhetorical Perspective on Informed Choice in Midwifery." Rhetor: Journal of the Canadian Society for the Study of Rhetoric 2. Retrieved June 27, 2013. <http://uregina.ca/ rheaults/rhetor/2007/ spoel.pdf $>$.

Spoel, P. 2010.“How Do Midwives Talk with Women?” In J. Leach and D. Dysart-Gale, eds., Rhetorical Questions of Health and Medicine (pp. 97-128). Lanham, MD: Rowman \& Littlefield.

Strauss, A. and J. Corbin. 1990. Basics of Qualitative Research: Grounded Theory Procedures and Techniques. Newbury Park, CA: Sage.

Wetherell, M., S. Taylor and S. Yates, eds. 2001. Discourse as Data: A Guide for Analysis. London and Milton Keynes: Sage and The Open University. 